\title{
Alternaria alternata causes pre-harvest discolouration in Backhousia myrtifolia leaf
}

\author{
Sarana Sommano • Daryl C. Joyce • Son Quang Dinh • \\ Bruce D'Arcy
}

Received: 4 March 2011 / Accepted: 13 July 2011 /Published online: 26 July 2011

(C) Australasian Plant Pathology Society Inc. 2011

\begin{abstract}
Backhousia myrtifolia is an Australian native plant cultivated for cut flowers and foliage. A leaf browning syndrome, with unknown cause, became problematic for the floriculture industry in the years 2003-2004. Alternaria alternata was isolated consistently from brown leaf lesions on potted nursery plants and pathogenicity was confirmed by Koch's postulates. This is the first report of $A$. alternata on B. myrtifolia that is a possible cause of leaf discolouration in B. myrtifolia.
\end{abstract}

Keywords Australian native plant · Browning · Cut flower

Backhousia myrtifolia is an Australian native plant grown in subtropical Queensland and New South Wales. Ruptured leaf and flower tissues give off a cinnamon-like aroma, which accounts for the plant's common name of "Cinnamon Myrtle". This species has been cultivated in recent years as a

\footnotetext{
S. Sommano $(\bowtie) \cdot$ D. C. Joyce $\cdot$ B. D’Arcy

School of Agriculture and Food Sciences,

The University of Queensland,

Gatton, Qld 4343, Australia

e-mail: s.sommano1@uq.edu.au

\section{C. Joyce}

Department of Employment, Economic Development and Innovation, Agriscience Queensland,

PO Box 5083, SCMC, Nambour, QLD 4560, Australia

\section{S. Q. Dinh}

Department of Primary Industries,

Biosciences Research Division, Knoxfield Centre, Private Bag 15,

Ferntree Gully Delivery Centre, Vic 3156, Australia
}

cut flower crop. It has aesthetically beautiful dark green leaves and lime-green to white flowers which pleases Japanese flower markets (Lim-Camacho et al. 2006). However without knowing the clear causes, its cut foliage and flowers suffer from browning and/or blackening spots, which later expand to become brown lesions approximately $0.5 \mathrm{~cm}$ in diameter after harvest and during storage at low temperature. The symptoms were initially detected in northern Australia (QLD), but have since more been found in southern regions (NSW) (Ekman et al. 2008). This has become a problem for the export industry. Chilling injury and dehydration during storage were initially suggested as main triggers of this discolouration (Ekman et al. 2008).

Brown to black spots on the leaves of potted $B$. myrtifolia plants were first observed during July to September 2008 on 4-year-old B. myrtifolia potted stock $(n=80)$ at the nursery on The University of Queensland's Gatton campus $\left(27^{\circ} 33^{\prime} \mathrm{S}, 152^{\circ} 20^{\prime} \mathrm{E}\right)$. Approximately $30 \%$ of plants showed discolouration on their fully developed leaves. The visible discolouration developed on the leaf surface as tiny spots that expanded to brown lesions, which then covered the whole leaf surface (Fig. 1). Leaves with brown lesions were harvested and transferred to the laboratory in a plastic container lined with wet paper towels. Leaf tissue of approximately $2.5 \mathrm{~mm}^{2}$ was cut from the edge of lesions which included both discoloured and adjacent healthy tissues. These cut tissues were surface sterilised in $75 \%(\mathrm{v} / \mathrm{v})$ ethanol for $60 \mathrm{~s}$, dried, then placed onto PDA media in Petri dishes and incubated at room temperature $\left(25^{\circ} \mathrm{C}\right)$ in a black light (Sylvania ${ }^{\circledR}$ black lightblue F 18 w/BLB-T8, Japan) chamber on a $12 \mathrm{~h}$ on-off cycle. Five-ten pieces from the same leaf were placed on the Petri dishes and there were 5 replicate dishes for each of 
the three plants tested. After 10 days of incubation, whitebrown mycelia grew from approximately $70-80 \%$ of the cut tissue tested. The fungal colonies (mycelia) from the explants were sub-cultured on fresh PDA media. Growth for 10 days on PDA media yielded brownish fungal colonies with white - grey hyphae (Fig. 2a). Conidiophores grew individually or in small groups. They were straight or branched, pale to greenish-brown, 5-20 $\mu \mathrm{m}$ long and with one or many conidial scars. The conidia were $0.25-0.5 \mu \mathrm{m}$ long and often in branched chains. They were elongated, smooth, oval-shaped and pale to olive brown. These spores were usually multi-septate with longitudinal and/or transverse septa (Fig. 2b, c). After Ellis (1971), the fungus was identified as an Alternaria species, probably A. Alternata Isolates were sent to the Queensland Department of Employment, Economic Development and Innovation (DEEDI) and morphologically confirmed to be $A$. alternata . Three isolates were assigned the herbarium accession codes BRIP 52221, BRIP 52222 and BRIP 52223 according to their different dates of collection on July 1st 2008, September 3rd 2008 and September 8th 2008, respectively.

Koch's postulates (Walker et al. 2006) were conducted in three separate experiments using the isolate BRIP 52221. In the first experiment, small agar plugs $\left(5 \mathrm{~mm}^{2}\right)$ with mycelium were placed on the abaxial surface of the leaves (non-wounded). There were three replicate leaves for each of the three plants tested. Each replicate consisted of one mature and one immature leaf placed in a Petri dish lined with a single layer of moistened filter paper. The dishes were sealed with Parafilm ${ }^{\circledR}$ to achieve high humidity and incubated as above. The development of brown lesions of 10-15 mm diam. was observed consistently on both immature and mature leaves after 10-14 days (Fig. 3a, b). Fungal isolation and purification from artificially inoculated lesions were performed as described earlier. Ten-day-old
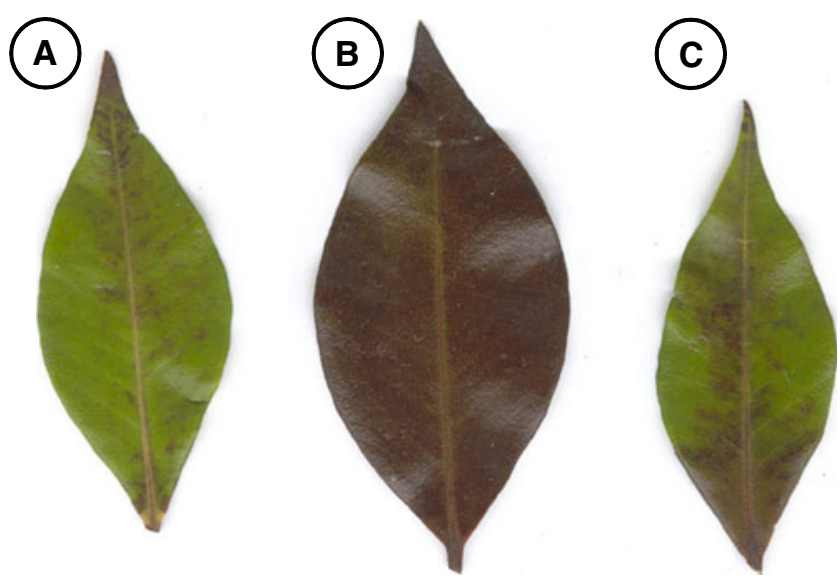

Fig. 1 Backhousia myrtifolia leaf discolouration symptoms observed during winter 2008: black spots (a), whole leaf turned black (b), and black spots and black lesion (c)

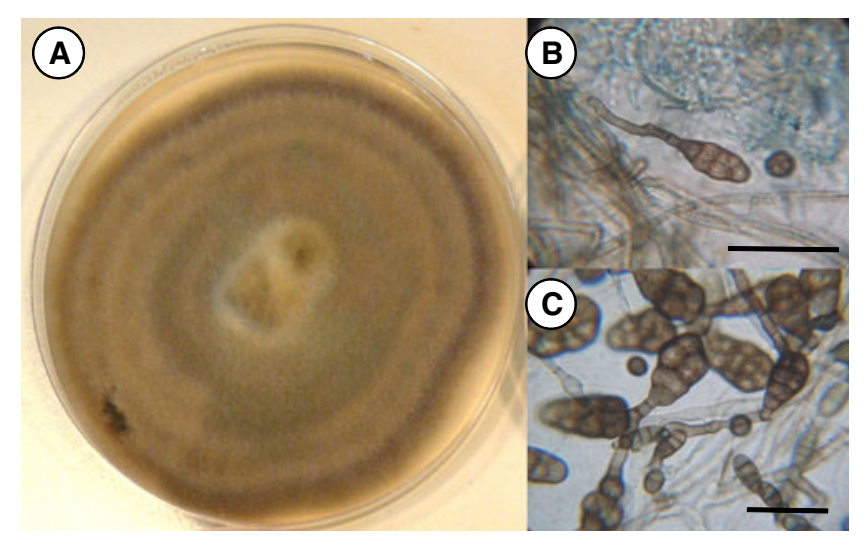

Fig. 2 Purified colony of Alternaria alternata isolate BRIP 52221 (a) and microscope views of spore morphology showing conidia, septa and hyphae of culture BRIP $52221(\mathbf{b}, \mathbf{c})$. Scale bars $=30 \mu \mathrm{m}$

single cultures on PDA media were used for pathogen identification by morphology.

In the second experiment, a suspension of $5 \times 10^{4}$ conidia/mL was used as inoculum. Detached leaves were excised from the top (immature), middle (young mature) and bottom (old mature) of the stem for each of the three plants tested. Leaf tips approximately $0.3-0.5 \mathrm{~cm}$ long were cut off and the leaves were sterilised as described above. Inoculation was performed by dipping the cut edge of leaves into the conidial suspension for $60 \mathrm{~s}$. Leaves were placed in sealed Petri dishes lined with wet paper and incubated at room temperature. Samples from each of the three categories (i.e., immature, young mature and old mature) were in duplicate. The control leaves were dipped in distilled water. Brown lesions developed at the cut edges of inoculated leaves after 10 days, particularly on immature and young mature leaves (Fig. 3c). Non-inoculated control leaves remained asymptomatic.

In the final experiment, attached leaves on 1-year-old potted plants $(n=3)$ were inoculated following the method of Inoue and Nasu (2000) with minor modifications. Briefly, sterilised filter paper $\left(0.3 \mathrm{~cm}^{2}\right)$ was dipped into a conidial suspension for $3 \mathrm{~min}$ and then secured with Micropore ${ }^{\mathrm{TM}}$ tape onto intact mature healthy leaves $(n=3 /$ plant). The control plants were inoculated with filter paper dipped in distilled water on the leaves. The whole plants were then covered with a perforated plastic bag to maintain high humidity. Treated plants were held in the laboratory at room temperature. Discolouration was observed after 10 days on all inoculated leaves. However, non-inoculated control leaves remained asymptomatic (Fig. 3d). This report suggested A. alternata is a possible cause of discolouration in B. myrtifolia leaves. Future works on pathogenicity of the three isolates, inoculation on floral tissue and infection during postharvest storage are to be conducted. 
Fig. 3 Koch's postulates experiment with mycelium inoculated onto detached immature (a) and mature (b) of Backhousia myrtifolia; arrows indicate mycelial inoculum. Leaf inoculation by conidia suspension (c) $\left(5 \times 10^{4}\right.$ conidia/mL) onto detached leaves of immature (arrow head 1), young mature (arrow head 2) and old mature (arrow head 3) leaves, and discolouration symptoms on an attached leaf after inoculation on the plant with the spore suspension $(\mathbf{d})$. Scale bars $=0.5 \mathrm{~cm}$

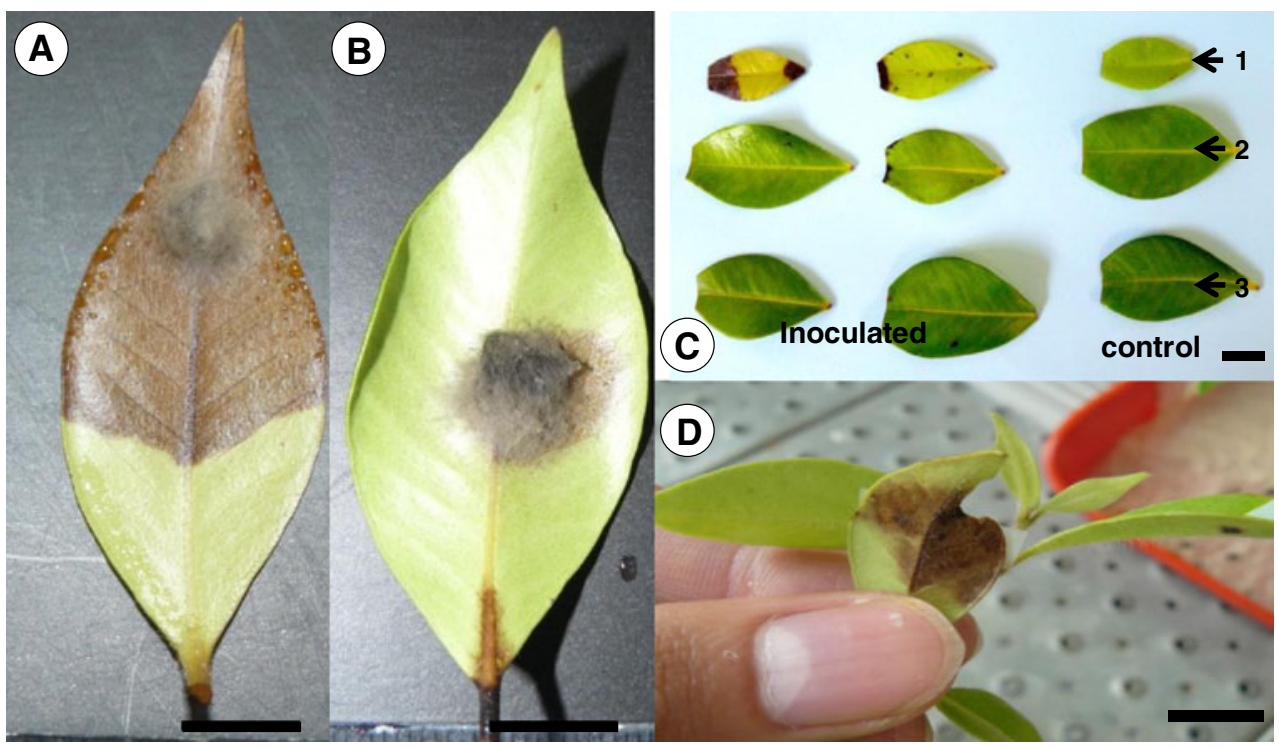

Acknowledgements The authors gratefully acknowledge Mr. Tony Cooke, DEEDI (Brisbane, Australia) for fungal identification and lodgement of herbarium accessions.

\section{References}

Ekman J, Eyre J, Joyce D (2008) Flowers by Sea-Improving market access for Australian wildflowers. Gosford Horticul- tural Institute NSW (Department of Primary Industries KINGSTON ACT)

Ellis MB (1971) Dematiaceous hyphomycetes. C.A.B. International, Surrey

Inoue K, Nasu H (2000) Black spot of peach caused by Alternaria alternata (Fr.) Keissler. J Gen Plant Pathol 66:18-22

Lim-Camacho L, Dunne T, Firrell C (2006) The Backhousia Project: a value chain alliance for Australian native cut flower to Japan. Acta Horticulturae 699:269-276

Walker L, LeVine H, Jucker M (2006) Koch's postulates and infectious proteins. Acta Neuropathol 112:1-4 